\title{
Bontly on Harm and the Non-Identity Problem
}

\author{
Erik Carlson and Jens Johansson* \\ Uppsala University \\ ${ }^{\star}$ Corresponding author. Email: jens.johansson@filosofi.uu.se
}

(Received 11 March 2019; revised 28 May 2019; accepted 28 May 2019; first published online 22 July 2019)

\begin{abstract}
The 'non-identity problem' raises a well-known challenge to the person-affecting view, according to which an action can be wrong only if it affects someone for the worse. In a recent article, however, Thomas $\mathrm{D}$. Bontly proposes a novel way to solve the non-identity problem in person-affecting terms. Bontly's argument is based on a contrastive causal account of harm. In this response, we argue that Bontly's argument fails even assuming that the contrastive causal account is correct.
\end{abstract}

\section{Introduction}

Derek Parfit famously introduced the following thought experiment. ${ }^{1}$

Risky or Safe: Imagine that our community must choose between two energy policies, 'Risky' and 'Safe'. If we choose Risky, the standard of living will be slightly higher for the next two centuries. However, Risky involves a considerable risk of a catastrophe in the further future. We choose Risky, which results in a catastrophe two hundred years from now, killing thousands of people. Suppose also that if we had chosen Safe, a completely disjoint but equally large group of people would have been alive two hundred years from now. Since the catastrophe would then have been avoided, these people's lifetime well-being level would have been much higher.

Intuitively, it was morally wrong for us to choose Risky. (To make this intuition maximally strong, suppose that we knew for certain that Risky would lead to a catastrophe in the far future.) Assuming that the people killed in the catastrophe have lives that are on balance worth living, however, our choosing Risky rather than Safe does not appear to affect them for the worse. After all, they would never have lived at all if we had chosen Safe. But if nobody is affected for the worse by our choosing Risky, how can this choice be morally wrong?

\footnotetext{
${ }^{1}$ D. Parfit, 'Future Generations: Further Problems', Philosophy \& Public Affairs 11 (1982), pp. 113-72. Our presentation of the example differs slightly from Parfit's.

(C) Cambridge University Press 2019. This is an Open Access article, distributed under the terms of the Creative Commons Attribution licence (http://creativecommons.org/licenses/by/4.0/), which permits unrestricted re-use, distribution, and reproduction in any medium, provided the original work is properly cited.
} 
Risky or Safe is an illustration of what Parfit dubbed the 'non-identity problem'. In Parfit's view, a solution to this problem will need to involve abandoning the 'person-affecting view', according to which an action can be wrong only if it affects someone for the worse. However, many philosophers find the person-affecting view highly plausible and have attempted to solve the non-identity problem in ways that are compatible with it. One interesting such attempt has recently been made by Thomas D. Bontly. ${ }^{2}$ Bontly argues that our choosing Risky harms the future people, by causing the catastrophe. As Bontly points out, however, establishing this does not yield the desired conclusion that choosing Risky is wrong. It must also be shown that choosing Risky does not benefit the victims of the catastrophe, or at least not to a greater extent than it harms them. Since we are assuming that these victims have a positive lifetime level of well-being, and that they would never have existed at all if we had chosen Safe, it appears that choosing Risky does benefit them more than it harms them. Bontly argues, however, that recognizing the causal nature of harm, and the contrastive nature of causation, will help us see that this appearance is deceptive, and that our choosing Risky in no way benefits the victims of the catastrophe (or anyone living at that time). Thus, Bontly's conclusion is that our choosing Risky harms the victims to some extent, and does not benefit them to any extent. If this is correct, the wrongness of choosing Risky can be explained in person-affecting terms. In what follows, we will present Bontly's argument in more detail, and argue that it does not succeed.

\section{Bontly's view}

Bontly bases his argument on the following account of harm (and benefit):

The Contrastive Causal Theory of Harm (CC): An action $x$ harms (benefits) a person $S$ to some extent (pro tanto) if and only if there is some event or state of affairs $d$ and some contrast class $d^{*}$, such that (i) the agent's doing $x$ rather than some contrast class $x^{*}$ causes $d$ rather than $d^{*}$, and (ii) $d$ makes $S$ worse (better) off than $d^{*}$ would have done. An action $x$ harms (benefits) a person $S$ overall or all things considered if and only if the extent to which $x$ harms (benefits) $S$ exceeds the extent (if any) to which $x$ benefits (harms) $S^{3}$

The notion of a contrast class is explained as follows: 'Unless there is an explicit contrast in the statement, the contrast class for $[x]$ is contextually determined; think of it as the set of possible actions, the performance of which we are willing to take seriously as alternatives to the performance by the agent of $[x] .^{4}$

According to Bontly, CC has several virtues. As opposed to purely counterfactual comparative accounts of harm it can, he claims, handle the notorious 'pre-emption problem'. Furthermore, the contrastive element makes the theory immune to problems stemming from alleged counterexamples to the transitivity of causation. We shall not

\footnotetext{
${ }^{2}$ T. D. Bontly, 'Causes, Contrasts, and the Non-Identity Problem', Philosophical Studies 173 (2016), pp. 1233-51.

${ }^{3}$ This formulation is a conjunction, with minor notational and linguistic changes, of Bontly's harm principles (5) and (2f), together with his assumption that harms and benefits should be given a parallel treatment (Bontly, 'Causes', p. 1236, n. 4). Taken literally, it is strange to claim that we can perform and cause contrast classes. Presumably, what Bontly means is that we can perform actions, and cause events or states of affairs, that are elements in contrast classes.

${ }^{4}$ Bontly, 'Causes', p. 1247.
} 
discuss whether these advantages are real. Our focus will be solely on CC's implications for the non-identity problem.

In Risky or Safe, the relevant contrast class to our choosing Risky consists of our choosing Safe. Bontly assumes that causing someone to exist, rather than never exist, can neither harm nor benefit her, since no one has any well-being level in possible worlds in which she never exists. Although this assumption is controversial, we shall not question it. ${ }^{5}$ Given the assumption, CC implies that our choosing Risky rather than Safe can harm or benefit a future person only if it causes something given which she has a life at a certain well-being level, rather than something given which she would have a life at a different well-being level (as opposed to having no life at all).

Bontly asks us to consider a specific future person, Mike, who lives two hundred years from now. Mike's life contains many good things, such as a rewarding job, a happy marriage, and a sailboat. Assuming CC, although Mike's life would not have contained these good things if we had chosen Safe instead of Risky, our choosing Risky does not benefit him by causing them. For it is not the case that, had we chosen Safe, Mike would have lived a life without these good things. Instead, he would never have lived at all. Concerning his sailboat, for example, our choosing Risky rather than Safe does not cause Mike to live his actual life, rife with sea-sprayed adventure, rather than a less happy landlubber life. Instead, our choosing Risky rather than Safe causes Mike to have his actual life rather than no life at all. Hence, our choosing Risky does not benefit Mike, insofar as his sailing is concerned. And likewise for the other good things in Mike's life. The situation is the same concerning other people living at that future time. Hence, our choosing Risky does not benefit them.

By contrast, Bontly contends, our choosing Risky does harm Mike, assuming that he is a victim of the catastrophe. Bontly writes:

[O] ur choosing Risky rather than Safe causes the future catastrophe to occur rather than not, and the future catastrophe is worse for the future people than events in its absence would have been - that is, they would have been better off without it ... ${ }^{6}$

In other words, because our choosing Risky rather than Safe causes the future catastrophe to occur rather than not, and the catastrophe makes Mike worse off than its nonoccurrence would have done, CC entails that our choosing Risky harms him. Likewise for other people living at that future time.

Thus, Bontly claims, since our choosing Risky rather than Safe harms future people to some extent and does not benefit them to any extent, it follows from CC that our choice harms future people overall. This provides a person-affecting explanation of why it was wrong to choose Risky.

\section{Critique of Bontly}

Bontly's argument is not convincing, even assuming the truth of CC.

Consider again Mike's sailboat. We agree with Bontly that our choosing Risky rather than Safe does not cause Mike to own a sailboat rather than live a landlubber life (something that would have made him overall worse off). For had we chosen Safe, Mike would never have existed at all, and would thus not live a landlubber life. In other

\footnotetext{
${ }^{5}$ Bontly claims that the assumption is not necessary for his argument ('Causes', p. 1250). However, since it makes his argument stronger, we shall grant it here.

${ }^{6}$ Bontly, 'Causes', p. 1248.
} 
words, taking Mike's living a landlubber life as a contrast to his owning a sailboat will not deliver the result that our choosing Risky benefits Mike. Likewise, of course, for various related candidate contrasts, such as Mike's living without a sailboat - it too would not have taken place had we chosen Safe.

In the same way, however, our choosing Risky rather than Safe does not cause the occurrence of the catastrophe rather than Mike's living a life in which the catastrophe does not occur (something that would have made Mike overall better off). For, again, had we chosen Safe, Mike would never have existed at all, and would thus not live a life in which the catastrophe does not occur. In other words, taking Mike's living a life in which the catastrophe does not occur as a contrast to the occurrence of the catastrophe will not deliver the result that our choosing Risky harms Mike. Likewise, of course, for various related candidate contrasts, such as Mike's surviving the catastrophe - it too would not have taken place had we chosen Safe.

However, there is another way to reach the result that our choosing Risky harms Mike. For Bontly seems to be right in his claim that our choosing Risky rather than Safe causes the future catastrophe to occur rather than not - at least on one reading. Of course, it does not cause the catastrophe to occur rather than to exemplify the property offailing to occur: if we had chosen Safe, the catastrophe would never have existed at all (since it would not occur), and would thus not exemplify any property. But plausibly, our choosing Risky rather than Safe does cause the occurrence of the catastrophe rather than its not being the case that the catastrophe occurs. After all, had we chosen Safe, it would not have been the case that the catastrophe occurs. Moreover, Bontly is right that Mike's lifetime well-being level would have been higher if it had not been the case that the catastrophe occurs. The nearest possible world in which it is not the case that the catastrophe occurs is not one in which Mike never exists, but one in which he lives a longer and happier life. We agree with Bontly, then, that CC implies that Risky harms Mike to some extent.

But in the very same way, CC also implies that Risky benefits Mike. Our choosing Risky rather than Safe causes Mike to own a sailboat rather than not - at least on the Bontly-friendly reading of 'rather than not' in the previous paragraph. Of course, our choosing Risky rather than Safe does not cause Mike to own a sailboat rather than to exemplify the property of not owning a sailboat: if we had chosen Safe, Mike would never have existed, and would thus not exemplify any property. But our choosing Risky rather than Safe does cause Mike's owning a sailboat rather than its not being the case that he owns a sailboat. After all, had we chosen Safe, it would not have been the case that Mike owns a sailboat. Moreover, Mike's lifetime well-being level would have been lower if it had not been the case that he owns a sailboat. The nearest possible world in which it is not the case that Mike owns a sailboat is not one in which Mike never exists, but one in which he lives a less happy life. CC implies, then, that our choosing Risky benefits Mike to some extent. Since analogous remarks hold for the other good things in Mike's life, and Mike's lifetime well-being level is positive, CC also implies that our choosing Risky benefits him overall. ${ }^{7}$

\footnotetext{
${ }^{7}$ Two anonymous referees have suggested that the relevant contrast to the catastrophe is not its not being the case that the catastrophe occurs, but some non-catastrophic event that would have happened at the time and place of the catastrophe had we chosen Safe. Presumably, that event does not require Mike's non-existence, and would thus have made him better off than the catastrophe does. Taking that event as the contrast to the catastrophe, then, will deliver the result that our choice of Risky harms Mike to some extent. However, this makes no difference to our argument, for once again corresponding remarks hold for the good things
} 
At the end of his article, Bontly indicates that our choosing Risky rather than Safe causes Mike to die prematurely rather than not. Similar remarks apply here, however. It seems correct that our choice causes Mike's dying prematurely rather than its not being the case that he dies prematurely (without which he would have been better off). For if we had chosen Safe, it would not have been the case that Mike dies prematurely, since one has to exist at some point in order to die prematurely. But again, our choice similarly causes Mike's owning a sailboat rather than its not being the case that he owns a sailboat (without which he would have been worse off). As before, moreover, because Mike would have never existed if we had chosen Safe, our choosing Risky rather than Safe does not cause Mike's dying prematurely rather than living a longer and happier life.

At one point, Bontly mentions a principle that implies that our choice actually does cause Mike's dying prematurely rather than living a longer and happier life. According to this principle, causation is 'differentially transitive':

DTC: If $c$ rather than $c^{*}$ causes $d$ rather than $d^{*}$, and $d$ rather than $d^{\star}$ causes $e$ rather than $e^{\star}$, then $c$ rather than $c^{\star}$ causes $e$ rather than $e^{\star}$.

Our choosing Risky rather than Safe causes the occurrence of the catastrophe rather than its not being the case that the catastrophe occurs, and the occurrence of the catastrophe rather than its not being the case that the catastrophe occurs causes Mike's dying prematurely rather living a longer and happier life. Hence, DTC implies that our choosing Risky rather than Safe causes Mike's dying prematurely rather than living a longer and happier life.

Bontly does not commit himself to DTC, however, and we think that Risky or Safe is a clear counterexample to it. Furthermore, DTC also yields the result that our choosing Risky benefits Mike. Presumably, there is some event $E$ occurring within Mike's lifetime e.g. someone introducing him to sailing - without which he would not have owned a sailboat. Our choosing Risky rather than Safe causes $E$ 's occurring rather than its not being the case that $E$ occurs (for note that its not being the case that $E$ occurs does not require Mike's existence), and $E$ 's occurring rather than its not being the case that $E$ occurs causes Mike's owning a sailboat rather than living a less happy life without a sailboat (for note that its not being the case that E occurs is compatible with Mike's existence). By DTC, then, our choosing Risky rather than Safe causes Mike's owning a sailboat rather than living a less happy life without a sailboat. An implausible result - but no more implausible than the claim that our choice causes Mike's dying prematurely rather than living a longer and happier life. ${ }^{9}$

in Mike's life. Perhaps this is easiest to see if we focus on an event $E$ that is responsible for Mike's becoming a sailor - say, Mike's being introduced to sailing at a talk in Speakers' Corner. Suppose some non-sailing-related event $E^{\star}$ would have taken place there and then, instead of $E$, if we had chosen Safe, and that Mike would have never got into sailing (or anything of comparable value for him) if $E^{\star}$ had occurred. Presumably, $E^{\star}$ does not require Mike's non-existence, and would thus have made him worse off than $E$ does. Taking $E^{\star}$ as the contrast to $E$, then, will deliver the result that our choice of Risky benefits Mike to some extent. Similar remarks obviously apply to his rewarding job, his happy marriage, etc.

${ }^{8}$ Bontly's formulation of the principle ('Causes', p. 1246) differs in trivial respects from ours.

${ }^{9}$ For helpful comments we are grateful to Olle Risberg and several anonymous referees. Work for this article was supported by grant P14-0212:1 from Riksbankens Jubileumsfond and grant 2018-01361 from Vetenskapsrådet.

Cite this article: Carlson E, Johansson J (2019). Bontly on Harm and the Non-Identity Problem. Utilitas 31, 477-481. https://doi.org/10.1017/S0953820819000220 